\title{
The Impact of Timing of Stent Removal on the Incidence of UTI, Recurrence, Symptomatology, Resistance, and Hospitalization in Renal Transplant Recipients
}

\author{
Ziad Arabi $\mathbb{D D}^{1,2,3}$ Khalefa Al Thiab ${ }^{1 D},{ }^{2,4}$ Abdulrahman Altheaby ${ }^{1 D},{ }^{1,2,3}$ \\ Mohammed Tawhari (D, ${ }^{1,2,3}$ Ghaleb Aboalsamh, ${ }^{2,3,5}$ Mohamad Almarastani, ${ }^{2,3,5}$ \\ Samy Kashkoush, ${ }^{2,3,5}$ Mohammed F Shaheen, ${ }^{2,3,5}$ Abdulrahman Altamimi, ${ }^{2,3,5}$ \\ Lina Alnajjar, ${ }^{6}$ Rawan Alhussein, ${ }^{7}$ Raghad Almuhiteb, ${ }^{7}$ Bashayr Alqahtani, ${ }^{7}$ \\ Rayana Alotaibi, ${ }^{7}$ Marah Alqahtani, ${ }^{7}$ Yahya Ghazwani, ${ }^{2,3,8}$ Wael O'Hali ${ }^{10,},{ }^{2,3,5}$ \\ and Khalid Bin Saad ${ }^{2,3,5}$ \\ ${ }^{1}$ Division of Adult Transplant Nephrology, King Abdulaziz Medical City, Riyadh, Saudi Arabia \\ ${ }^{2}$ King Abdullah International Medical Research Center, Riyadh, Saudi Arabia \\ ${ }^{3}$ College of Medicine, King Saud Bin Abdulaziz University for Health Sciences, Riyadh, Saudi Arabia \\ ${ }^{4}$ Pharmaceutical Care Department, King Abdulaziz Medical City, Riyadh, Saudi Arabia \\ ${ }^{5}$ Department of Hepatobiliary Sciences and the Organ Transplant Center, King Abdulaziz Medical City, Riyadh, Saudi Arabia \\ ${ }^{6}$ Department of Pharmacy Practice, College of Pharmacy, Princess Nourah Bint Abdulrahman University, Riyadh, Saudi Arabia \\ ${ }^{7}$ College of Pharmacy, Princess Nourah Bint Abdulrahman University, Riyadh, Saudi Arabia \\ ${ }^{8}$ Division of Urology, King Abdulaziz Medical City, Riyadh, Saudi Arabia
}

Correspondence should be addressed to Ziad Arabi; ziadarabi@yahoo.com

Received 25 April 2021; Revised 28 May 2021; Accepted 12 June 2021; Published 3 July 2021

Academic Editor: Gian Luigi Adani

Copyright (c) 2021 Ziad Arabi et al. This is an open access article distributed under the Creative Commons Attribution License, which permits unrestricted use, distribution, and reproduction in any medium, provided the original work is properly cited.

Purpose. To evaluate the impact of early ( $<3$ weeks) versus late ( $>3$ weeks) urinary stent removal on urinary tract infections (UTIs) post renal transplantation. Methods. A retrospective study was performed including all adult renal transplants who were transplanted between January 2017 and May 2020 with a minimum of 6-month follow-up at King Abdulaziz Medical City, Riyadh, Saudi Arabia. Results. A total of 279 kidney recipients included in the study were stratified into 114 in the early stent removal group (ESR) and 165 in the late stent removal group (LSR). Mean age was 43.4 \pm 15.8 ; women: $n$ : $114,40.90 \%$; and deceased donor transplant: $n$ : 55 , $19.70 \%$. Mean stent removal time was $35.3 \pm 28.0$ days posttransplant $(14.1 \pm 4.6$ days in the ESR versus $49.9 \pm 28.1$ days in LSR, $p<0.001)$. Seventy-four UTIs were diagnosed while the stents were in vivo or up to two weeks after the stent removal "UTIs related to the stent" $(n=20,17.5 \%$ in ESR versus $n=54,32.7 \%$ in LSR; $p=0.006)$. By six months after transplantation, there were 97 UTIs ( $n=36,31.6 \%$ UTIs in ESR versus $n=61,37 \%$ in LSR; $p=0.373$ ). Compared with UTIs diagnosed after stent removal, UTIs diagnosed while the stent was still in vivo tended to be complicated (17.9\% versus 4.9\%, $p: 0.019)$, recurrent (66.1\% versus $46.3 \%$; $p$ : $0.063)$, associated with bacteremia ( $10.7 \%$ versus $0 \%$; $p$ : 0.019$)$, and requiring hospitalization ( $61 \%$ versus $24 \%$, $p$ : 0.024$)$. Early stent removal decreased the need for expedited stent removal due to UTI reasons (rate of UTIs before stent removal) $(n=11,9 \%$ in the early group versus $n=45,27 \%$ in the late group; $p=0.001$ ). The effect on the rate of multidrug-resistant organisms (MDRO) was less clear $(33 \%$ versus $47 \%, p: 0.205)$. Early stent removal was associated with a statistically significant reduction in the incidence of UTIs related to the stent ( $\mathrm{HR}=0.505,95 \% \mathrm{CI}: 0.302-0.844, p=0.009)$ without increasing the incidence of urological complications. Removing the stent before 21 days posttransplantation decreased UTIs related to stent (aOR: 0.403, CI: 0.218-0.744). Removing the stent before 14 days may even further decrease the risk of UTIs (aOR: 0.311, CI: 0.035- 2.726). Conclusion. Early ureteric stent removal defined as less than 21 days post renal transplantation reduced the incidence of UTIs related to stent without increasing the incidence of urological complications. UTIs occurring while the ureteric stent still in vivo were notably associated with bacteremia and hospitalization. A randomized trial will be required to further determine the best timing for stent removal. 


\section{Background}

Ureteric stents are shown to decrease post renal transplant urological complications but are believed to increase the risk of urinary tract infections (UTIs) [1-7]. Hence, our practice has changed over the years. Initially, we adopted a protocol where the ureteric stents remained in vivo for 2 months after living donor kidney transplantation (LKT) and 2-3 months after deceased donor kidney transplant (DKT). In 2018, our center modified its protocol of ureteric stent removal to the following:

(1) Ureteric stents to be removed "routinely": within 2-4 weeks posttransplant.

(2) Ureteric stents to be removed "expeditiously" if a patient develops UTIs. It is recommended to remove the stent once the infection is controlled.

(3) Urinary stent to be removed "emergently" in the case of migrated stent to the urethra or in the case of unstable patients with severe sepsis due to UTIs or in the case of fungal infection [8].

In this study, we aim to examine the impact of protocol change leading to earlier ureteric stent removal on the incidence and characteristics of UTIs post kidney transplantation. Three weeks' timing has been shown in previous studies to reduce the risk of UTIs without an increase in major urological complications and hence was adopted in this study as a cutoff value $[5,9]$.

\section{Methodology}

After obtaining the institutional board review approval (RC20/138/R), a retrospective study was conducted including adult renal transplant recipients at King Abdulaziz Medical City, Riyadh, Saudi Arabia, from January 2017 to May 2020 with 6 months follow-up. Renal transplant recipients were excluded if they were diagnosed with UTI within one month prior to transplantation or if they experienced early graft failure. All patients received either antithymocyte globulin (ATG) or basiliximab plus the standard triple immunosuppressant combination: tacrolimus, prednisone, and mycophenolic acid. Data about patients' characteristics and UTI outcomes were collected, including incidence, risk factors, symptomatology, prevalence of multidrug-resistant organisms (MDRO), rate of hospitalization, and treatment. Owing to the lack of consensus on the best timing for stent removal, we used 3 weeks' time to separate early from late stent removal. The early stent removal groups had the stent removed within 3 weeks from the renal transplant date, while the late stent removal group had the stent removed anytime beyond 3 weeks. We considered UTIs as "stent-related UTIs" if UTIs occurred while the stent is still in place up until two weeks after removing the stent. UTIs were considered caused by MDRO if the causative organism was resistant to at least one agent of three or more antimicrobial categories.

UTIs were classified according to their symptoms into [10-12]:
(1) Asymptomatic bacteriuria; $>10^{5}$ colony-forming units $(\mathrm{cfu}) / \mathrm{mL}$

(2) Simple (uncomplicated) UTI: positive urine culture in addition to any urinary symptoms such as dysuria, urgency, frequency, or suprapubic pain, but no systemic symptoms.

(3) Complicated UTI: positive urine culture in addition to systemic symptoms such as fever, chills, flank, and/or allograft pain.

(4) Complicated UTI with bacteremia.

(5) Recurrent UTI: more than one UTIs in the first 6 months with the same or different microorganisms.

We reviewed the timing of UTIs and compared UTIs before and after stent removal regarding their incidence, recurrence, symptomatology, resistance, type of treatment, and need for hospitalization. We also studied the urological complications in the early versus the late stent removal groups.

2.1. Statistical Analysis. All analyses were performed using IBM SPSS software 23.0 (IBM Co., Armonk, NY, USA). Continuous variables were presented as mean (SD). Categorical variables were expressed as proportions (percentages). We compared data using $t$-test, Mann-Whitney $U$ test, chi-squared test, or Fisher's exact test as appropriate. We used logistic regression analysis to calculate UTI odds ratio, with adjustments for age and gender. Survival analysis was performed using the Cox regression model and adjusted for age and gender. All statistical tests were two-sided, and $P$ values $<0.05$ were considered statistically significant.

\section{Results}

(1) Patients' characteristics: a total of 279 kidney recipients were included in the study (114 in the early group and 165 in the late group). Mean age was $43.4 \pm 15.8$; of them $114(40.90 \%)$ were women and 55 (19.70\%) were deceased donor transplant recipients. Mean stent removal time was $35.3 \pm 28.0$ days posttransplant $(14.1 \pm 4.6$ days in the early group versus $49.9 \pm 28.1$ days in the late group, $p<0.001$ ) (Table 1)

(2) Secondary analysis: the two groups were statistically different with regard to the donor type, serum creatinine at 6 months, and the type of antibiotics prophylaxis used. Secondary analysis showed that these factors were not contributing to the risk of UTIs and recurrence in our study. On the other hand, age $>40$, female gender, transplantation abroad, and neurogenic bladder were contributing factors of UTIs [(OR: 2.176, CI: 1.187-3.986), (OR: 5.008, CI: 2.74-9.156), (OR: 5.008, CI: 2.607-27.05), and (OR: 5.646, CI: 1.016-31.379), respectively]. These factors were distributed symmetrically between the early and the late groups.

(3) Timing of UTIs in relation to stent removal: as shown in Figure 1, most of the UTIs diagnosed during the first 6 months posttransplantation 
TABLE 1: Renal transplant recipients' characteristics.

\begin{tabular}{|c|c|c|c|c|}
\hline & Total 279 & Early 114 & Late 165 & $p$ \\
\hline Stent removal time $($ mean $\pm \mathrm{SD})$ & $35.3 \pm 28.0$ & $14.1 \pm 4.6$ & $49.9 \pm 28.1$ & $<0.001$ \\
\hline Age $($ mean $\pm S D)$ & $43.4 \pm 15.8$ & $44.1 \pm 16.2$ & $42.9 \pm 15.5$ & 0.544 \\
\hline \multicolumn{5}{|l|}{ Gender } \\
\hline $\begin{array}{l}\text { Male } \\
\text { Female }\end{array}$ & $\begin{array}{c}165 \\
59.10 \% \\
114 \\
40.90 \% \\
\end{array}$ & $\begin{array}{c}68 \\
59.60 \% \\
46 \\
40.40 \% \\
\end{array}$ & $\begin{array}{c}97 \\
58.80 \% \\
68 \\
41.20 \% \\
\end{array}$ & 0.902 \\
\hline \multicolumn{5}{|l|}{ Donor type } \\
\hline Living & $\begin{array}{c}55 \\
19.70 \% \\
224 \\
80.30 \%\end{array}$ & $\begin{array}{c}15 \\
13.20 \% \\
99 \\
86.80 \%\end{array}$ & $\begin{array}{c}40 \\
24.20 \% \\
125 \\
75.80 \%\end{array}$ & 0.031 \\
\hline Transplant abroad & $\begin{array}{c}21 \\
7.50 \%\end{array}$ & $\begin{array}{c}11 \\
9.60 \%\end{array}$ & $\begin{array}{c}10 \\
6.10 \%\end{array}$ & 0.356 \\
\hline Preemptive transplant & $\begin{array}{c}21 \\
7.6 \%\end{array}$ & $\begin{array}{c}9 \\
8.00 \%\end{array}$ & $\begin{array}{c}12 \\
7.30 \%\end{array}$ & 1 \\
\hline \multicolumn{5}{|l|}{ Diabetes mellitus } \\
\hline $\begin{array}{l}\text { Type I } \\
\text { Type II }\end{array}$ & $\begin{array}{c}25 \\
26.60 \% \\
69 \\
73.40 \% \\
\end{array}$ & $\begin{array}{c}8 \\
25.80 \% \\
23 \\
74.20 \% \\
\end{array}$ & $\begin{array}{c}17 \\
27.00 \% \\
46 \\
73.00 \% \\
\end{array}$ & 1 \\
\hline \multicolumn{5}{|l|}{ Induction therapy } \\
\hline $\begin{array}{l}\text { Basiliximab } \\
\text { ATG }\end{array}$ & $\begin{array}{c}107 \\
38.40 \% \\
172 \\
61.60 \% \\
\end{array}$ & $\begin{array}{c}68 \\
60.20 \% \\
46 \\
40.40 \% \\
\end{array}$ & $\begin{array}{c}104 \\
63.00 \% \\
61 \\
37.00 \% \\
\end{array}$ & 0.617 \\
\hline \multicolumn{5}{|l|}{ Serum creatinine in $\mathrm{mmol} / \mathrm{L}($ mean $\pm \mathrm{SD})$} \\
\hline $\begin{array}{l}\text { At } 1 \text { month } \\
\text { At } 6 \text { months }\end{array}$ & $\begin{array}{c}103.7 \pm 47.2 \\
99.0 \pm 34.0\end{array}$ & $\begin{array}{l}99.7 \pm 34.5 \\
93.5 \pm 21.1\end{array}$ & $\begin{array}{l}106.4 \pm 54.2 \\
102.7 \pm 40.2\end{array}$ & $\begin{array}{l}0.244 \\
0.014\end{array}$ \\
\hline Rejection within 6 months & $\begin{array}{c}22 \\
7.90 \%\end{array}$ & $\begin{array}{c}6 \\
5.30 \%\end{array}$ & $\begin{array}{c}16 \\
9.70 \%\end{array}$ & 0.416 \\
\hline $\mathrm{BK}$ & $\begin{array}{c}19 \\
6.80 \%\end{array}$ & $\begin{array}{c}9 \\
7.90 \%\end{array}$ & $\begin{array}{c}10 \\
6.10 \%\end{array}$ & 0.632 \\
\hline \multicolumn{5}{|l|}{ UTI antibiotic prophylaxis } \\
\hline $\begin{array}{l}\text { TMP/SMX double strength + norfloxacin } \\
\text { TMP/SMX single strength }\end{array}$ & $\begin{array}{c}70 \\
25.10 \% \\
209 \\
74.90 \% \\
\end{array}$ & $\begin{array}{c}13 \\
11.40 \% \\
101 \\
88.60 \% \\
\end{array}$ & $\begin{array}{c}57 \\
34.50 \% \\
108 \\
65.50 \% \\
\end{array}$ & $<0.001$ \\
\hline \multicolumn{5}{|l|}{ Pretransplant urological abnormalities } \\
\hline Urethral stricture & $\begin{array}{c}11 \\
3.90 \%\end{array}$ & $\begin{array}{c}5 \\
4.40 \%\end{array}$ & $\begin{array}{c}6 \\
3.60 \%\end{array}$ & 0.763 \\
\hline Neurogenic bladder & $\begin{array}{c}10 \\
3.60 \%\end{array}$ & $\begin{array}{c}3 \\
2.60 \%\end{array}$ & $\begin{array}{c}7 \\
4.20 \%\end{array}$ & 0.535 \\
\hline Vesicoureteral reflux (VUR) & $\begin{array}{c}7 \\
2.50 \%\end{array}$ & $\begin{array}{c}1 \\
0.90 \%\end{array}$ & $\begin{array}{c}6 \\
3.60 \%\end{array}$ & 0.246 \\
\hline Emergent stent removal due to stent migration & $\begin{array}{c}6 \\
2.1 \%\end{array}$ & $\begin{array}{c}5 \\
1.7 \%\end{array}$ & $\begin{array}{c}1 \\
0.04 \%\end{array}$ & 0.048 \\
\hline
\end{tabular}

occurred while the stent was still in place extending to up to two weeks post stent removal. Afterward, UTIs become sporadic and less frequent.

(4) UTIs and other outcomes in relation to stent removal: there were 74 UTIs occurred while the stent was still in vivo-related to the stent- $(n=20,17.5 \%$ in the early group versus $n=54,32.7 \%$ in the late group; $p=0.006)$. By six months after transplantation, there were 97 additional UTIs $(n=36,31.6 \%$
UTIs in the early group versus $n=61,37 \%$ in the late group; $p=0.373$ ) (Table 2).

(5) The risk of UTIs in relation to stent removal: ESR significantly decreased the incidence of UTI related to stent $(\mathrm{HR}=0.505,95 \% \mathrm{CI}: 0.302-0.844$, $p=0.009)$. The positive effect of ESR became numerically but not statically significant when reviewing the total UTIs by 6 months (HR: 0.787 , 95\% CI: 0.474-1.305). Figure 2 shows the adjusted 


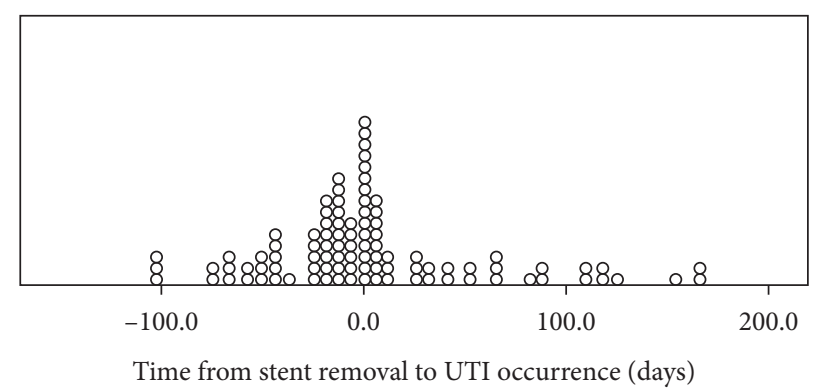

FigURE 1: Time from stent removal to UTI occurrence. Most of the UTIs during the first 6 months post renal transplantation are stent related (occurs while the stent in place and up to two weeks post stent removal). After the stent removal, UTIs clearly become sporadic and less frequent.

TABLE 2: Summary of the outcomes of early versus late stent removal.

\begin{tabular}{|c|c|c|c|c|}
\hline & $\begin{array}{c}\text { Total } \\
279\end{array}$ & $\begin{array}{c}\text { Early } \\
114 \\
\end{array}$ & $\begin{array}{c}\text { Late } \\
165\end{array}$ & $p$ \\
\hline UTIs related to stent & $\begin{array}{c}74 \\
26 \%\end{array}$ & $\begin{array}{c}20 \\
17.5 \%\end{array}$ & $\begin{array}{c}54 \\
32.7 \%\end{array}$ & 0.006 \\
\hline UTIs by 6 months & $\begin{array}{c}97 \\
34 \% \\
\end{array}$ & $\begin{array}{c}36 \\
29 \% \\
\end{array}$ & $\begin{array}{c}61 \\
36 \% \\
\end{array}$ & 0.373 \\
\hline UTI recurrence in the first 6 months & $\begin{array}{c}56 \\
57,7 \% \\
\end{array}$ & $\begin{array}{c}19 \\
52 \% \\
\end{array}$ & $\begin{array}{c}37 \\
60 \% \\
\end{array}$ & 0.288 \\
\hline MDRO by 6 months & $\begin{array}{c}41 \\
42.2 \%\end{array}$ & $\begin{array}{c}12 \\
33.30 \%\end{array}$ & $\begin{array}{c}29 \\
47.50 \%,\end{array}$ & 0.205 \\
\hline UTIs before stent (requiring expedited stent removal) & $\begin{array}{c}56 \\
20 \%\end{array}$ & $\begin{array}{c}11 \\
9.6 \%\end{array}$ & $\begin{array}{c}45 \\
27 \%\end{array}$ & $<0.001$ \\
\hline Urological complications of renal transplantation & & & & \\
\hline Urinary leak & $\begin{array}{c}3 \\
1.10 \% \\
3 \\
1 \%\end{array}$ & $\begin{array}{c}0 \\
0.0 \% \\
1 \\
0.36 \%\end{array}$ & $\begin{array}{c}3 \\
1.80 \% \\
2 \\
0.64 \%\end{array}$ & 0.272 \\
\hline
\end{tabular}

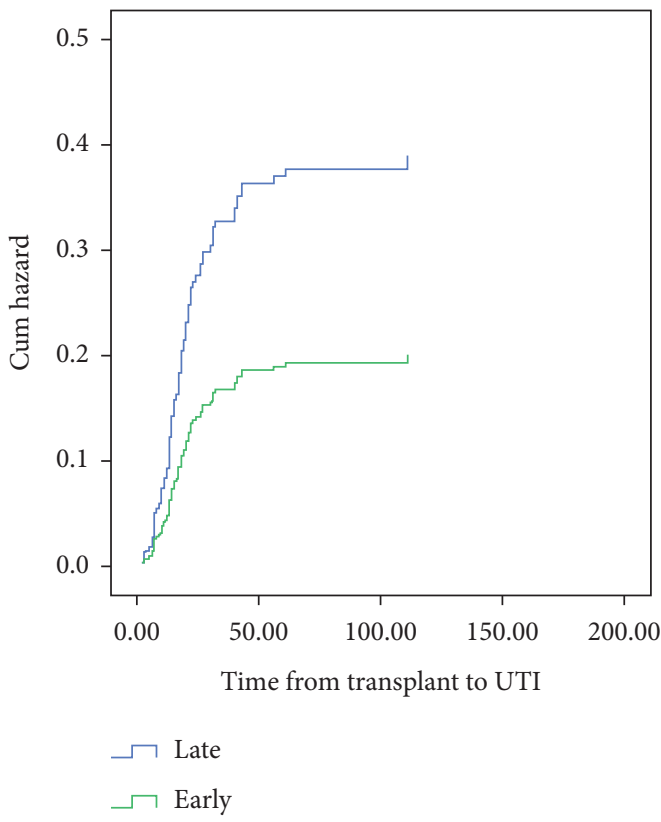

(a)

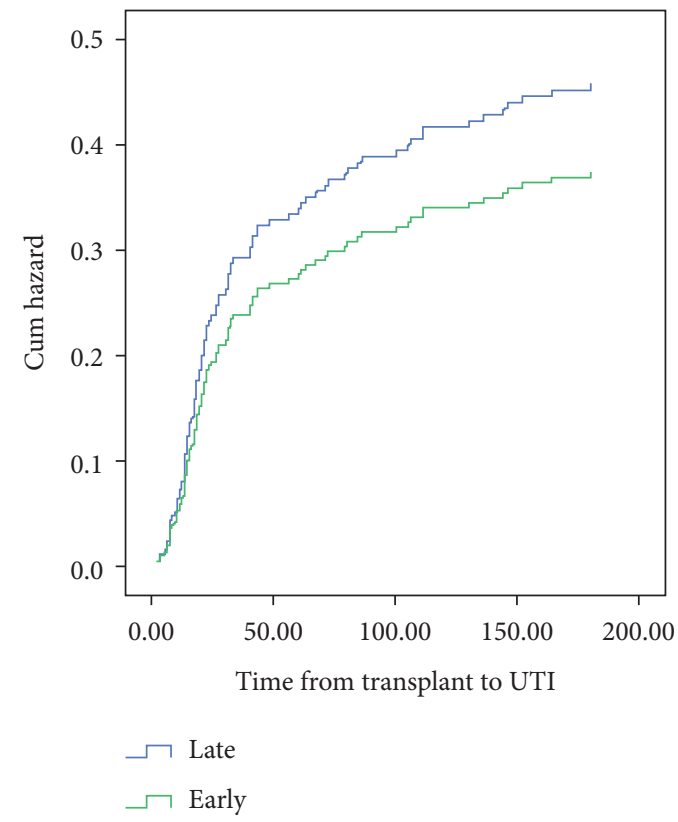

(b)

FIgURE 2: Adjusted Cox proportional hazard ratio. (a) UTIs related to stent. ESR has significantly reduced the incidence of UTIs related to stent $(\mathrm{HR}=0.505,95 \% \mathrm{CI}(0.302$ to 0.844$), p=0.009)$. (b) UTIs by 6 months. The positive effect of ESR became numerically but not statically significant when reviewing the total UTIs by 6 months (HR: 0.787 , CI: $0.474-1.305$ ). 
Cox proportional hazard ratio of UTIs in both groups.

(6) Further comparison was done in regard to the incidence, distribution, and symptomatology of UTIs before and after stent removal in the (late versus early) stent removal groups. And the results are shown in Figure 3 and Table 3.

UTIs before stent removal were much higher in the late group $(n=45,27 \%$ in the late group versus $n=11,9 \%$ in the early group, $p<0.001$ ) (Figure 3 ). UTIs before stent removal are considered as an indication for "expedited" stent removal as per our center protocol (Figure 3).

In addition, UTIs before stent removal when compared to UTIs after stent removal were more complicated $(17.9 \%$ versus $4.9, p: 0.019)$ and more associated with bacteremia (10.7\% versus $0 \%$; $p$ : $0.019)$ and more associated with hospitalization (61\% versus $24 \%, p: 0.024)$. UTIs before stent removal also recurred at higher numerical rate $(66.1 \%$ versus 46.3\%; p: 0.063) (Table 3).

(7) Of note, only one of the 6 patients who underwent emergent stent removal for non-UTIs reason developed UTIs ( 5 cases versus one, $p$ : 0.048 ) as shown in Table 1. The incidence of MDRO in the early versus late stent removal groups was (33\% versus $47 \%, p: 0.205)$, as shown in Table 3.

(8) When comparing the odds ratio of UTIs related to stent in the relation to the timing of stent removal, it is noted that removing the stent before 21 days posttransplantation decreased UTIs related to stent (aOR: 0.403, CI: 0.218-0.744). Furthermore, removing the stent before 14 days may further decrease the risk of UTIs (aOR: 0.311, CI: 0.035- 2.726) (Table 4).

(9) The incidence of urological complications post renal transplantation was low and did not reach a statistical difference between the two groups as shown in Table 2

\section{Discussion}

Prophylactic ureteric stenting during kidney transplantation is routinely performed at our center. This approach is shown to reduce major urological complications (MUCs). However, it significantly increases the risk of UTIs post kidney transplantation while the stent is in situ $[2,7,9,13-17]$. Additionally, stent manipulation at the time of removal by cystoscopy can also introduce more UTIs [18].

In our study, the incidence of UTIs during the first 6 months posttransplantation was $34 \%$ which is comparable to the rates reported by other studies $[15,19]$. The majority of these UTIs (76.3\%) occurred while the stent was still in place and up to two weeks after (i.e., they were "stent-related UTIs"). Beyond that time, UTIs became sporadic and less frequent. This observation suggests that utilizing the concept of "stent-related UTIs" instead of "UTIs in the first 3- or 6months posttransplantation" maybe more logical and is likely to be a better indicator about the impact of the timing of urinary stent removal on the UTIs. Otherwise, the impact of stent on UTIs can get "diluted with time" and studies may become underpowered to detect significance difference between the two arms $[5,20,21]$.

Early removal of ureteric stents has been recommended to decrease UTIs by multiple studies and guidelines $[15,16]$. A recent systematic review and meta-analysis including 14 studies including three randomized controlled trials with a total of 3216 kidney transplant recipients, showed significant reduction of UTIs when stents were removed earlier than three weeks (OR: $0.49,95 \%$ CI: 0.33 to $0.75, p=0.0009$ ) and without increasing the incidence of urinary leakage compared to delayed removal after 3 weeks [9]. In this study, ESR ( $<3$ weeks) significantly reduced the incidence of UTI related to stent $(\mathrm{HR}=0.505,95 \% \mathrm{CI}: 0.302$ to $0.844 ; p=0.009)$. This beneficial effect remained numerically significant at 6 months (HR: 0.787, CI: 0.474-1.305).

Multiple studies have examined the impact of stent removal at different intervals from renal transplantation including at 4 weeks [6], 3 weeks [5], 2 weeks [4], one week $[22,23]$, or 5 days [24] post renal transplantation. These studies have shown that the early removal of ureteric stents following kidney transplantation may potentially reduce the incidence of UTI without significant increase of major urological complications. In our study, removing the stent before 21 days posttransplantation decreased UTIs related to stent (aOR: 0.403, CI: 0.218-0.744). Removing the stent before 14 days further decrease the risk of UTIs (aOR: 0.311, CI: 0.035-2.726).

Urinary stents are also risk factors for UTIs recurrence [7]. In our study, the recurrence rate before stent removal was $66 \%$, and it decreased to $46 \%$ post stent removal ( $p$ : $0.06)$. ESR also led to slight numerical decrease in the rate of MDRO (33\% versus 47\%; $p$ : 0.2 ). This observation requires further study [25].

In our study, UTIs while the stent was still in situ tended to be more complicated (17.9\% versus $4.9 \%$; $p$ : 0.019$)$, associated with bacteremia (10.7\% versus $0 \% ; p$ : 0.019$)$, and more often resulted in hospitalizations (61\% versus $34 \%$; $p$ : $0.024)$. ESR seems to limit the window of these more serious UTIs. This important finding of ureteral stents as a contributing factor of blood stream infections due to UTIs is inline with similar findings observed in few other studies [26-28]. In our cohort, the risk of UTIs with bacteremia significantly decreased once the stent was removed (6 cases before stent removal versus zero after stent removal; $p=0.019$ ).

For the above reasons, the occurrence of the first UTI post renal transplantation is considered sufficient indication-in our center-to have the stent removed expeditiously once the infection is treated [29]. This is to minimize the risk of recurrence and the risk of more complicated UTIs.

ESR did not increase the urological complications in our study. The incidence of major urological complications (MUCs) post renal transplantation in our recipients $(80 \%$ 


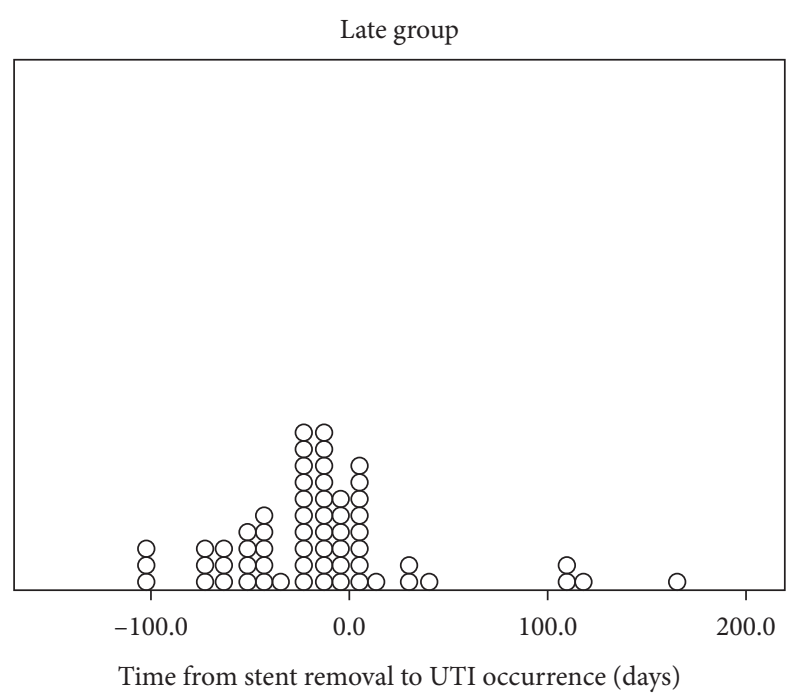

(a)

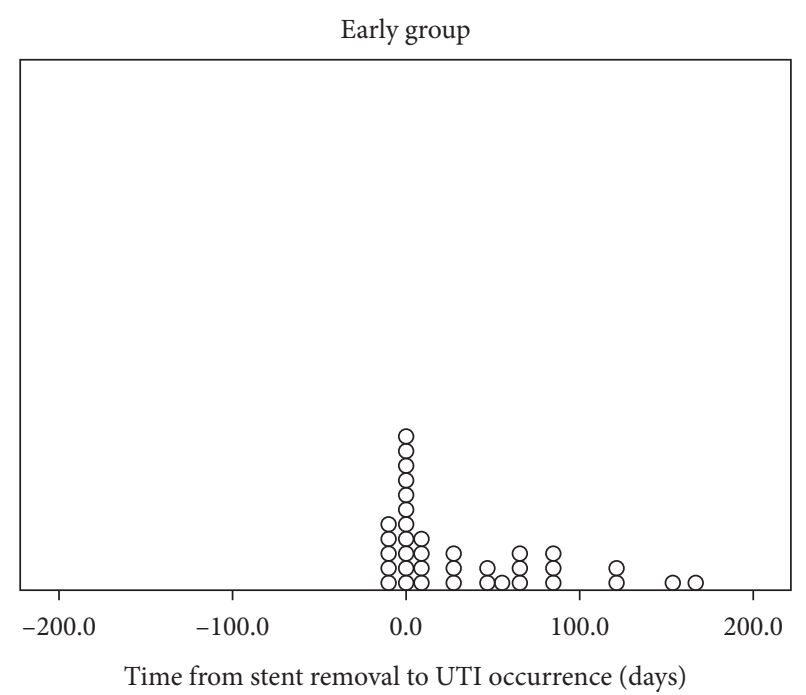

(b)

FIGURE 3: UTI distribution before and after stent removal. (a) In the late stent removal group. (b) In the early stent removal group. UTIs before stent removal were much higher in the late group $(n=45,27 \%$ versus $n=11,9 \%$ in the early group; $p<0.001)$.

TABLE 3: UTIs before versus after stent removal (recurrence, symptoms, MDRO, and inpatient treatment).

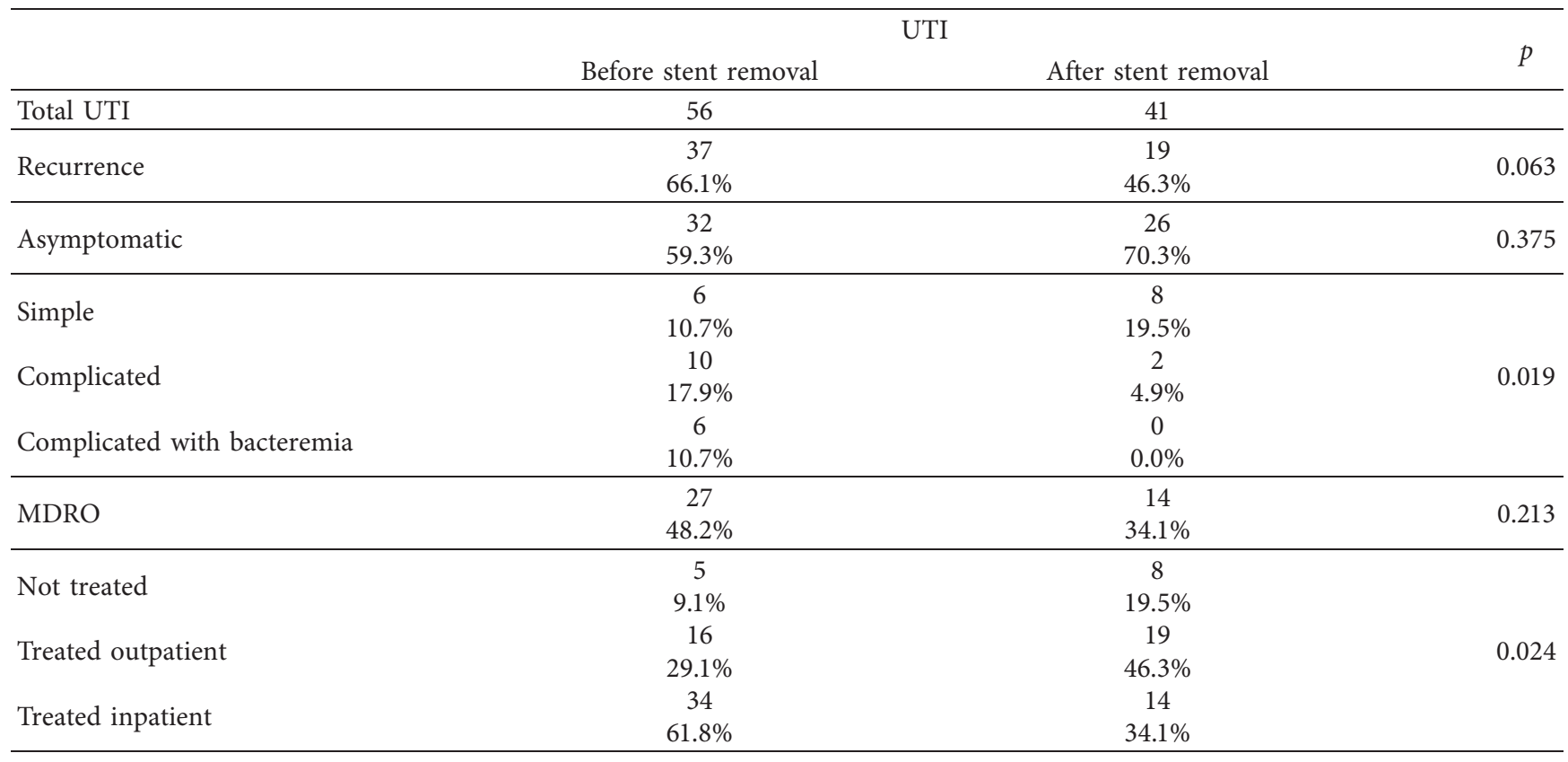

TABLE 4: Unadjusted and adjusted odds ratio for age and sex for UTIs related to stent.

\begin{tabular}{lcccccrrr}
\hline Stent removed & No UTIs & UTIs & OR & & $95 \%$ CI & aOR & 95\% CI \\
\hline$\leq 7$ days & $\begin{array}{c}7 \\
87.5 \%\end{array}$ & $\begin{array}{c}1 \\
12.5 \%\end{array}$ & 0.378 & 0.047 & 3.204 & 0.311 & 0.035 & 2.726 \\
\hline$\leq 14$ days & $\begin{array}{c}50 \\
86.2 \%\end{array}$ & $\begin{array}{c}8 \\
13.8 \%\end{array}$ & 0.376 & 0.169 & 0.836 & 0.357 & 0.155 \\
\hline$\leq 21$ days & $\begin{array}{c}94 \\
82.5 \%\end{array}$ & $\begin{array}{c}20 \\
17.5 \%\end{array}$ & 0.437 & 0.244 & 0.783 & 0.403 & 0.218 & 0.744 \\
\hline 28 days & $\begin{array}{c}28 \\
120\end{array}$ & $\begin{array}{c}28 \\
18.9 \%\end{array}$ & 0.431 & 0.250 & 0.744 & 0.392 & 0.219 & 0.701 \\
\hline
\end{tabular}

aOR: adjusted OR. Removing the stent before 21 days posttransplantation decreased UTIs related to stent (aOR: 0.403, CI: 0.218-0.744). Removing the stent before 14 days may further decrease the risk of UTIs (aOR: 0.311, CI: 0.035- 2.726). 
living kidney donor) remained low (only 2.1\%). There was no statically significant difference between the early versus the late groups. Of note, out of the 55 deceased donor renal transplants in our study, there were no urinary leaks in either early or late groups, and there were only two cases of ureteral stenosis in the late group. ESR in this subgroup is also suggested [30, 31].

Studies have shown that, while there is an estimated cost saving for routine prophylactic stent versus no-stenting of about \$200 per patient [6], early ureteric stent removal (8 days versus 15 days) can further reduce UTIs and reduce hospitalization with an estimated cost saving of $\$ 2390$ per patient [20].

Our study has several points of strength and weakness. Despite the retrospective nature of this study and the small number of patients, this study was able to show the impact of timing of stent removal on the incidence of UTI, recurrence, symptomatology, resistance, and hospitalization in our renal transplant recipients. It was also able to show positive impact of expediting the logistics of urinary stent removal in our center.

\section{Conclusion}

Early ureteric stent removal before 21 days post renal transplantation reduced the incidence of UTIs related to stent without increasing the incidence of urological complication. ESR decreased the risk of UTI recurrence, the risk of complicated UTI, bacteremia, or need for hospitalization due to UTIs.

\section{Data Availability}

The data used to support the findings of this study may be released upon application to the institutional review board at King Abdulaziz Medical City (KAMC), who can be contacted at IRB@ngha.med.sa.

\section{Conflicts of Interest}

The authors declare that they have no conflicts of interest.

\section{References}

[1] R. S. Mangus and B. W. Haag, "Stented versus nonstented extravesical ureteroneocystostomy in renal transplantation: a metaanalysis," American Journal of Transplantation, vol. 4, no. 11, pp. 1889-1896, 2004.

[2] C. H. Wilson, A. A. Bhatti, D. A. Rix, and D. M. Manas, "Routine intraoperative ureteric stenting for kidney transplant recipients," The Cochrane Database of Systematic Reviews, vol. 4, Article ID Cd004925, 2005.

[3] C. V. Sansalone, G. Maione, P. Aseni et al., "Advantages of short-time ureteric stenting for prevention of urological complications in kidney transplantation: an 18-year experience," Transplantation Proceedings, vol. 37, no. 6, pp. 2511-2515, 2005.

[4] D. Yahav, H. Green, N. Eliakim-Raz, E. Mor, and S. Husain, "Early double J stent removal in renal transplant patients to prevent urinary tract infection - systematic review and metaanalysis of randomized controlled trials," European Journal of
Clinical Microbiology \& Infectious Diseases, vol. 37, no. 4, pp. 773-778, 2018.

[5] L. Huang, X. Wang, Y. Ma et al., "A comparative study of 3week and 6-week duration of double-J stent placement in renal transplant recipients," Urologia Internationalis, vol. 89, no. 1, pp. 89-92, 2012.

[6] A. Tavakoli, R. S. Surange, R. C. Pearson, N. R. Parrott, T. Augustine, and H. N. Riad, "Impact of stents on urological complications and health care expenditure in renal transplant recipients: results of a prospective, randomized clinical trial," Journal of Urology, vol. 177, no. 6, pp. 2260-2264, 2007.

[7] M. Ranganathan, M. Akbar, M. A. Ilham, R. Chavez, N. Kumar, and A. Asderakis, "Infective complications associated with ureteral stents in renal transplant recipients," Transplantation Proceedings, vol. 41, no. 1, pp. 162-164, 2009.

[8] Z. Arabi, A. Theaby, M. Farooqui, M. Abdalla, A. Hajeer, and K. Abdullah, "The national guard health affairs guidelines for the medical management of renal transplant patients," Journal of Kidney Diseases and Transplantation, vol. 29, no. 6, pp. 1452-1469, 2018.

[9] I. J. Visser, J. P. T. van der Staaij, A. Muthusamy, M. Willicombe, J. A. Lafranca, and F. J. M. F. Dor, "Timing of ureteric stent removal and occurrence of urological complications after kidney transplantation: a systematic review and meta-analysis," Journal of Clinical Medicine, vol. 8, no. 5, 2019.

[10] S. Greissman, A. Mattiazzi, M Mendoza et al., "Antimicrobial resistance and recurrent bacterial urinary tract infections in hospitalized patients following kidney transplantation: a single-center experience," Transplant Infectious Disease An Official Journal of the Transplantation Society, vol. 22, no. 4, Article ID e13337, 2020.

[11] J. D. Goldman and K. Julian, "Urinary tract infections in solid organ transplant recipients: guidelines from the American society of transplantation infectious diseases community of practice," Clinical Transplantation, vol. 33, 2019.

[12] C. A. B. Santos and C. Daniel, Kidney transplantation in adults: urinary tract infection in kidney transplant recipients. Uptodate, 2020, https://www-uptodate-com.ezproxy. alfaisal.edu/contents/kidney-transplantation-in-adults-urinarytract-infection-in-kidney-transplant-recipients?search=UTI \%20post\%20renal\%20transplant\&source=search_result \& selectedTitle $=1 \sim 150 \&$ usage_type $=$ default $\&$ display_rank $=1$.

[13] E. Vidal, C. Cervera, E Cordero et al., "Management of urinary tract infection in solid organ transplant recipients: consensus statement of the group for the study of infection in transplant recipients (GESITRA) of the Spanish society of infectious diseases and clinical microbiology (SEIMC) and the Spanish network for research in infectious diseases (REIPI)," Enfermedades Infecciosas Y Microbiologia Clinica, vol. 33, no. 10, pp. 679-e21, Article ID e671, 2015.

[14] X. Wu, Y. Dong, Y. Liu et al., "The prevalence and predictive factors of urinary tract infection in patients undergoing renal transplantation: a meta-analysis," American Journal of Infection Control, vol. 44, no. 11, pp. 1261-1268, 2016.

[15] E. R. Thompson, S. A. Hosgood, M. L. Nicholson, and C. H. Wilson, "Early versus late ureteric stent removal after kidney transplantation," The Cochrane Database of Systematic Reviews, vol. 1, no. 1, Article ID CD011455, 2018.

[16] J. D. Goldman and K. Julian, "Urinary tract infections in solid organ transplant recipients: guidelines from the American society of transplantation infectious diseases community," Clinical Transplantation, vol. 33, no. 9, Article ID e13507, 2019.

[17] F. Friedersdorff, S. Weinberger, N. Biernath, H. Plage, H. Cash, and N. El-Bandar, "The ureter in the kidney 
transplant setting: ureteroneocystostomy surgical options, double-J stent considerations and management of related complications," Current Urology Reports, vol. 21, no. 1, 3 pages, 2020.

[18] J. R. Gregg, C. L. Kang, T. R. Talbot et al., "Symptomatic urinary tract infections in renal transplant recipients after cystoscopy for ureteral stent removal," Urology Practice, vol. 4, no. 5, pp. 405-411, 2017.

[19] M. Giessing, "Urinary tract infection in renal transplantation," Arab Journal of Urology, vol. 10, no. 2, pp. 162-168, 2012.

[20] W. Parapiboon, A. Ingsathit, S. Disthabanchong et al., "Impact of early ureteric stent removal and cost-benefit analysis in kidney transplant recipients: results of a randomized controlled study," Transplantation Proceedings, vol. 44, no. 3, pp. 737-739, 2012.

[21] L. Soylu, O. U. Aydin, M. Atli et al., "Does early removal of double J stents reduce urinary infection in living donor renal transplantation?" Archives of Medical Science, vol. 15, no. 2, pp. 402-407, 2019.

[22] S. Liu, G. Luo, B. Sun et al., "Early removal of double-J stents decreases urinary tract infections in living donor renal transplantation: a prospective, randomized clinical trial," Transplantation Proceedings, vol. 49, no. 2, pp. 297-302, 2017.

[23] J.-F. Cai, W. Wang, W. Hao et al., "Meta-analysis of early versus late ureteric stent removal after kidney transplantation," Transplantation Proceedings, vol. 50, no. 10, pp. 3411-3415, 2018.

[24] P. Patel, I. Rebollo-Mesa, E. Ryan et al., "Prophylactic ureteric stents in renal transplant recipients: a multicenter randomized controlled trial of early versus late removal," American Journal of Transplantation, vol. 17, no. 8, pp. 2129-2138, 2017.

[25] T. Fleet, H. Kerr, S. L. Y. Paine, A. Harford, and M. Davis, "Does the use of ureteral stents in renal transplant allografts increase the risk of multi-drug resistant urinary tract infections or decrease long term function of the allograft?" American Journal of Transplantation, vol. 13, no. suppl 5, p. 13, 2013, https://atcmeetingabstracts.com/abstract/doesthe-use-of-ureteral-stents-in-renal-transplant-allograftsincrease-the-risk-of-multi-drug-resistant-urinary-tractinfections-or-decrease-long-term-function-of-the-allograft/.

[26] S.-W. Wu, K.-S. Liu, C.-K. Lin et al., "Community-acquired urinary tract infection in kidney transplantation: risk factors for bacteremia and recurrent infection," Journal of the Formosan Medical Association, vol. 112, no. 3, pp. 138-143, 2013.

[27] K. C. Abbott, J. D. Oliver, III, I. Hypolite et al., "Hospitalizations for bacterial septicemia after renal transplantation in the United States," American Journal of Nephrology, vol. 21, no. 2, pp. 120-127, 2001.

[28] A. Kritikos and O. Manuel, "Bloodstream infections after solid-organ transplantation," Virulence, vol. 7, no. 3, pp. 329-340, 2016.

[29] Z. Arabi, A. Theaby, M. Farooqui et al., "The National Guard Health Affairs guidelines for the medical management of renal transplant patients," Saudi Journal of Kidney Diseases and Transplantation, vol. 29, no. 6, pp. 1452-1469, 2018.

[30] M. Sarier, D. Seyman, S. Tekin et al., "Comparision of ureteral stent colonization between deceased and live donor renal transplant recipients," Transplantation Proceedings, vol. 49, no. 9, pp. 2082-2085, 2017.

[31] B. Appiya Ramamoorthy, P. Javangula Venkata Surya, and D. Darlington, "Early versus delayed double J stent removal in deceased donor renal transplant recipients: a prospective comparative study," Cureus, vol. 10, no. 7, Article ID e3006, 2018. 